MEI

II, vol. 5 $\mathrm{n}^{0} 9$

\title{
La gestión de los fondos fotográficos en el Archivo General de la Región de Murcia: una labor inagotable
}

\author{
Javier Castillo Fernández
}

Archivo General de la Región de Murcia

\section{Resumen}

Recibido el

05-12-2014

Aceptado en 27-12-2014

Tras explicar la relación del Archivo con la fotografía y el origen de sus fondos fotográficos, se describe el conjunto de procesos establecidos en los últimos años para gestionar, conservar y divulgar el aproximadamente millón de fotografías que custodia. Finalmente se presenta una relación descriptiva de sus principales fondos y colecciones fotográficas.

\section{Palabras clave}

Archivos fotográficos, gestión documental, clasificación de fondos fotográficos, descripción de fotografías, conservación de fotografías, digitalización, difusión, Región de Murcia.

\section{Title}

The management of photographic collections in the General Archives of the Region of Murcia: an inexhaustible work.

\begin{abstract}
After explaining the relationship of the Archive with photography and the origin of their photographic collections, the whole of processes established in recent years to manage, preserve and spread the estimated one million photographs that custody is described. Finally, a descriptive account of its main photographic funds and collections is presented.
\end{abstract}

\section{Keywords}

Photographic archives, records management, classification of photographic funds, description of photographs, photograph conservation, digitization, dissemination, Region of Murcia. 


\section{1.- El porqué de todo: origen e interés por los fondos fotográficos en el AGRM}

El Archivo General de la Región de Murcia, creado en 1996, es el centro archivístico encargado de recoger, conservar, describir y poner a disposición de los ciudadanos y de la administración los documentos generados por el gobierno de la Comunidad Autónoma de Murcia, así como de otras instituciones que le precedieron (Diputación Provincial y Consejo Regional de Murcia). Al mismo tiempo, gestiona en su misma sede el Archivo Histórico Provincial de Murcia, centro de titularidad estatal y gestión autonómica, dedicado a recibir la documentación sin vigencia administrativa producida por la Administración Periférica o Delegada del Estado en la Región. Por último, en su condición de Servicio de Archivos, es el responsable de ejecutar las políticas regionales en relación con los archivos y el patrimonio documental en su ámbito geográfico.

En la actualidad el Archivo General conserva casi trescientos cincuenta fondos y colecciones documentales, tanto de origen público como privado, en un moderno edificio inaugurado en 2005. Entre este conjunto documental, en los últimos años han cobrado una especial relevancia los de naturaleza fotográfica. La fotografía no es nueva en los archivos: desde aproximadamente el segundo tercio del siglo XX comienza a ser utilizada en la gestión administrativa común para dejar constancia de diversas actuaciones o acontecimientos. Por tanto, la fotografía -fundamentalmente en formato positivo- formará desde entonces parte de los expedientes administrativos, especialmente en determinadas áreas institucionales, como protocolo, obras públicas... Y esos expedientes, una vez cumplida su vigencia administrativa, han ido pasando de forma natural a los archivos, aunque no han recibido una especial atención en los criterios de conservación y descripción hasta fechas relativamente recientes.

Paralelamente, desde la década de los años ochenta del pasado siglo, el denominado patrimonio fotográfico comienza a cobrar una importancia creciente en España. Numerosas iniciativas, tanto públicas como privadas, a nivel estatal, autonómico y local, trataron de recuperar y de dar a conocer este inmenso patrimonio o lo que quedaba de él. En el ámbito de la Región de Murcia, el hito fundamental fue la creación, en 2001, del Centro Histórico Fotográfico de la Región de Murcia (CEHIFORM), establecido en Cartagena, con los objetivos de "conservación, restauración, recuperación, puesta en valor, promoción y difusión de todo material fotográfico antiguo y contemporáneo de interés para la Región de Murcia, en cuanto parte integrante de su patrimonio histórico" (Región de Murcia, 2001). Como primera actuación de sensibilización, organizó una gran exposición en 2003 bajo el título Fotografía en la Región de Murcia (Díaz Burgos, J. M. et al., 2003), que fue el primer intento serio de conocer el panorama histórico de la fotografía murciana. Su labor se centró en estos años en recuperar, mediante la adquisición, depósito o donación, y en con- 
servar adecuadamente diversos archivos fotográficos de interés, sobre todo de antiguos fotógrafos comerciales, entre los que destacan, por su volumen e interés, los de Fernando Navarro, José Casaú, Fotografía Martínez Blaya o Antonio Abellán. Al mismo tiempo, siguió dando a conocer, a través de exposiciones y la edición de catálogos - esencialmente mediante la colección "Fotógrafos Región de Murcia"1-, el legado de algunos de los más relevantes fotógrafos murcianos. En 2005 el CEHIFORM fue adscrito al Archivo General de la Región, que continuó su labor de recuperación y de difusión del acervo fotográfico murciano. En 2010, debido a los ajustes provocados por la crisis económica, el Centro como tal dejó de funcionar y sus fondos fueron trasladados a la sede del Archivo General, desde donde se ha continuado la labor de conservación y difusión de los mismos; fondos que se han visto incrementados notablemente en los últimos años.

\section{2.- ¿Qué tenemos?}

Como ya se ha apuntado, el Archivo General cuenta con dos grandes tipos de fondos fotográficos: por un lado, los procedentes de las administraciones públicas a las que sirve, transferidos regularmente al archivo; y, por otro, los de origen privado y de interés regional, en buena parte procedentes del CEHIFORM pero a los que hay que añadir los que han ingresado en los últimos cuatro años directamente al Archivo. El gran volumen y la diversidad de procedencias de los fondos fotográficos reunidos, así como el interés creciente por parte de los usuarios en este tipo de recursos, aconsejó otorgarles una entidad propia y darle así una mayor visibilidad dentro de la clasificación de fondos del archivo. Para ello, en 2011 los distintos conjuntos fotográficos se agruparon virtualmente, dentro del cuadro de organización de fondos del Archivo, formando el grupo de fondos "E. / Fondos y colecciones fotográficas"?. Y, dentro de este, bajo las siguientes subdivisiones, de acuerdo con su procedencia:
E.01. / Fotografías de instituciones públicas
E.02. / Fotografía comercial (estudios y fotógrafos)
E.03. / Fotoperiodismo
E.04. / Colecciones fotográficas privadas y de fotógrafos amateurs
E.05. / Colecciones temáticas de fotografía

El centro cuenta actualmente con setenta y dos fondos y colecciones fotográficas, tanto en formatos originales, como -en menor medida- en copia digital, que suman aproximadamente un millón cien mil fotografías, la más antigua 
de ellas datada en $1858^{3}$. Una selección de los más importantes de estos fondos se describe en el anexo final de este artículo. Los fondos, por otra parte, están en permanente crecimiento, tanto por identificación de material en expedientes ya custodiados en el Archivo o que ingresan a través de las transferencias, como por donaciones y adquisiciones de colecciones particulares.

Por lo que se refiere a la clasificación y organización de los conjuntos fotográficos se observa rigurosamente, como con cualquier tipo de fondo documental, el principio archivístico de procedencia. Es decir, la identificación clara del origen del fondo o colección, así como de su productor o productores ${ }^{4}$, vertebra toda la gestión del mismo, desde su recepción a su puesta a disposición de los usuarios finales.

\section{3.- ¿Cómo lo hacemos?: o cómo no morir en el intento. La gestión inte- gral de los fondos y colecciones fotográficas}

Ante tal volumen de fotografías, en diversos procedimientos, soportes y formatos, con desigual nivel de identificación y estado de conservación, contando con recursos humanos y materiales congelados e incluso decrecientes y con la dificultad añadida de unos materiales de conservación onerosos, se plantea una obligada y necesaria priorización a la hora de intervenir sobre los conjuntos fotográficos. Actualmente no es posible conocer con exactitud, ni acceder de forma sistemática, al total de imágenes fotográficas del Archivo puesto que no se ha podido aún tratar en su conjunto, siquiera de forma mínima. Para intentar paliar, en la medida de lo posible, estos inconvenientes se ha hecho hincapié en dos herramientas de gestión y de acceso a los objetos fotográficos: el inventario y el contactado digital, que se describen más adelante. Los criterios de intervención se establecen en función de la valoración del interés de las imágenes, combinando distintos parámetros como su importancia para la Región de Murcia, su contenido formal, informativo o artístico, su volumen, antigüedad, procedimiento, autoría, rareza o demanda potencial ${ }^{5}$. Algo similar al "plan de actuación” que definen Boadas, Casellas y Suquet (2001, pp. 124-127) y que expone, de forma más práctica, Casellas Serra (2007).

Los procesos aplicados a las fotografías se incardinan dentro de un modelo de gestión que abarca todas las fases del trabajo archivístico, desde su entrada en el centro hasta su puesta a disposición de los usuarios, pasando por el registro, limpieza, signaturado, instalación, descripción, digitalización y difusión. Pero, incluso, se adelantan al propio proceso de ingreso, puesto que -en algunos casos- se actúa de forma pro-activa para conseguir la recuperación de determinados fondos o colecciones de interés para el patrimonio fotográfico e histórico regional; y se prolongan al entorno del Archivo, creando sinergias o es- 
trategias de colaboración con colectivos o instituciones interesados en la fotografía.

\section{1.- Recuperación e ingreso de fondos fotográficos}

El primer paso en un centro como el Archivo General de la Región de Murcia, encargado de la protección y fomento del patrimonio documental autonómico, es, por tanto, el de la recuperación de archivos fotográficos de interés, mediante diferentes figuras: adquisición, donación, cesión. En relación con las compras de archivos fotográficos, en nuestro caso se han limitado a dos grandes fondos (el de Fotografía Casaú, realizado en 2001-2002, y el archivo del fotoperiodista Carlos Gallego, en 2008), así como a varias pequeñas colecciones. Conviene señalar que las limitaciones presupuestarias actuales han motivado que la política de adquisiciones se restrinja al máximo y se circunscriba sólo a aquellos casos de especial interés, oportunidad y economía. Actualmente se está fomentando la donación, haciendo ver a los potenciales donantes -además de la garantía de la preservación, no disgregación y difusión de su legado- que este tipo de cesiones también llevan aparejadas importantes inversiones por parte del Archivo en gastos de personal técnico, instalación, conservación, descripción y digitalización del material donado.

Otra fórmula para recuperar e incrementar el patrimonio fotográfico regional, aunque sea de forma virtual, ha consistido en la realización y cesión a favor del Archivo, de copias digitales de calidad de fotografías cuyos originales permanecen en manos de sus propietarios. Este fue uno de los objetivos del proyecto "Álbum familiar de la Región de Murcia"6, realizado en las localidades de Puerto Lumbreras (2007) y Cartagena (2008), aunque actualmente se sigue realizando, a menor escala, con particulares que llevan al Archivo sus colecciones fotográficas.

Como recomiendan Boadas, Casellas y Suquet (2001), tanto las adquisiciones como las donaciones deben quedar perfectamente documentadas e incluir, en el instrumento jurídico que las acredite, la cesión de los derechos de propiedad intelectual y de explotación y difusión de las imágenes. Asimismo, la autoría de la fotografía, siempre que se conoce, se respeta y explicita en la descripción.

En todo caso, conviene ser cautos y medir la capacidad del centro, puesto que asumir un legado fotográfico de varios miles -o incluso cientos de miles- de instantáneas puede comprometer las posibilidades y los recursos con que se cuenta durante bastante tiempo; y plantearnos si, por su tamaño y temática, debería ser este su archivo de destino o derivarlo a otro. Parece indudable que, en caso de duda y ante el peligro de desaparición, debe primar la salvaguarda preventiva del mismo. 
Tanto los ingresos de origen privado como los de origen público quedan asentados en el Registro general de entrada de fondos al Archivo. En este primer momento es importante recopilar cualquier información de contexto que pueda resultar relevante, tanto del productor (historia institucional o biografía profesional del autor, publicaciones sobre el mismo...) como del material fotográfico (localización de registros u otra información sobre fechas, lugares, personas y objetos representados en las fotografías).

\section{2.- Instalación y conservación}

La adecuada preservación de las fotografías es, como es sabido, una de las tareas que más recursos económicos consume. Tanto las instalaciones como el material de conservación son caros y el Archivo sólo cuenta con una asignación económica limitada para su adquisición. Asimismo, la manipulación y limpieza del material fotográfico debe realizarse con sumo cuidado y requiere de personal con experiencia, no siempre disponible, por lo que estas tareas no pueden acometerse de forma masiva o con premura.

Resulta imprescindible a la hora de gestionar cualquier nueva colección el reconocimiento de los procedimientos fotográficos, especialmente aquellos más antiguos y frágiles, para poder diagnosticar problemas de preservación que tengan o puedan tener a corto plazo, tratar de minimizarlos y aplicarles los métodos de conservación más adecuados. Para ello se tienen en cuenta las recomendaciones de diversos especialistas en la materia, como Pavão (2001), Mestre i Vergés (2003) y Lavédrine (2010).

El Archivo General ha concentrado en un depósito la mayor parte de sus fondos fotográficos. Además de la climatización del mismo, cuenta con equipamiento de armarios compactos, que permite optimizar el espacio. Por un lado se han instalado los álbumes y cajas de conservación de negativos ${ }^{7} \mathrm{y}$ diapositivas, y por otro los de positivos. Cada tipo de soporte cuenta con una sigla propia para su código de referencia o signatura de localización: FOT_NEG, para negativos, FOT_POS, para positivos ${ }^{8}$, FOT_DIG, para copias digitales de ori-

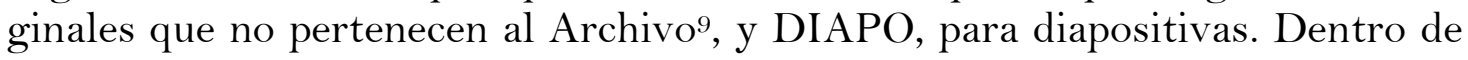
los negativos, en la medida de lo posible, se ha tratado de que cada contenedor sólo contenga formatos similares, en cuanto a soportes y dimensiones, separando además los negativos monocromos de los policromos (criterio este último que también se ha seguido con los positivos).

Queda pendiente determinar qué hacer con las fotografías que forman parte de expedientes administrativos. Los distintos especialistas no se ponen de acuerdo sobre si por motivos de conservación y de salvaguardia es conveniente o no, tal como se hace con otro tipo de los llamados "materiales especiales" (mapas, pla- 
nos, dibujos, grabados, etc.), extraerlas de los mismos e instalarlas en cajas de conservación adecuadas. En el Archivo General se comenzó a desinstalar aquellas instantáneas, fundamentalmente positivos -aunque no es infrecuente que se encuentren negativos, en cuyo caso no hay duda a la hora de trasladar dichas instantáneas a contenedores específicos- que aparecían en algunas series documentales específicas: patrimonio histórico, obras públicas, etc., garantizando en todo caso -mediante referencias cruzadas- su relación con el expediente de origen y su contexto de creación, pero actualmente esta tarea, compleja y laboriosa, no se realiza de forma sistemática, limitándonos en la mayoría de los casos a referir en la ficha descriptiva de la unidad documental la existencia de fotografías.

En el caso de la existencia de álbumes fotográficos originales se ha optado por conservarlos, especialmente si cuentan con valores artísticos, rotulaciones, anotaciones o cualquier otro tipo de información relevante, introduciéndolos en cajas de conservación homologadas. Consideramos que una determinada secuencia o presentación de las fotografías por parte de su productor o propietario ofrece una información adicional interesante sobre cuáles fueron los criterios que motivaron dicha ordenación. Sólo en aquellos casos en que no presentan valores estéticos o información relevante (por ejemplo, series de fotografías pegadas a hojas o cartulinas, en fundas comerciales de plástico o adhesivas) en las que, además, los materiales usados pueden afectar a la conservación de las originales, se procede a traspasar las fotografías a fundas y álbumes de conservación y, si se considera necesario, se realiza previamente una copia digital de la disposición originaria de las fotografías.

En todos los casos, pero especialmente cuando ingresan archivos fotográficos privados, se considera primordial recoger toda la información que se encuentre en los contenedores originales: cajas de negativos, rollos de película, sobres de positivos, etc., que nos ayudarán a identificar y datar el contenido de las imágenes. Además, conservamos este material, relacionándolo con los nuevos contenedores de las fotografías, para futuras consultas.

Tras la limpieza -realizada con el asesoramiento de personal especialista en conservación y restauración-, y de forma simultánea al ensobrado e instalación en contenedores de conservación de las fotografías, se procede a su signaturado y a la realización del inventario de las mismas, que consiste en la recogida de los datos básicos de las instantáneas; bien a nivel de unidad documental simple o, lo que es más frecuente, a nivel de unidad documental compuesta -reportaje-, lo que permite avanzar en la descripción de conjuntos documentales más amplios. Los datos mínimos de este inventario son: código de referencia, título o descripción genérica, fecha o fechas de captura, tipo de imagen (positivos o ne- 
gativos), tono (blanco y negro o color), soporte (vidrio, plástico o papel), dimensiones, estado de conservación y -en su caso- signatura de procedencia. A partir de esta somera información, en un segundo estadio se procederá a una descripción más exhaustiva de las fotografías en la aplicación de gestión archivística del centro.

\section{3.- Clasificación y descripción}

Resulta necesario aludir, aunque sea brevemente, a la clasificación de cada uno de los fondos fotográficos. En este caso, como en el resto, se tiende a realizar cuadros de clasificación funcionales que permitan clasificar las fotografías de acuerdo con las funciones y actividades de los productores de las mismas (Boadas, Casellas y Suquet, 2001, pp. 129-132). Así, por ejemplo, el fondo fotográfico del jurista y político Mariano Ruiz-Funes, se distingue entre los documentos gráficos personales (referidos a su familia y vida privada) de los documentos gráficos de su función docente y política, antes y después del exilio. En la medida de lo posible se evita realizar una clasificación a partir de las características de los soportes (negativos, positivos, color...), poco operativa para los usuarios; aunque en ocasiones, en tanto no se acomete la identificación global del contenido del material fotográfico, y en aras a un mejor control físico del fondo, se recurre a realizar una clasificación provisional de este tipo.

Como para cualquier otro tipo de fondos documentales la descripción es la llave para el control físico, la conservación y el acceso a las fotografías. Algunos de los fondos y colecciones acumulados, primero por el CEHIFORM y luego por el Archivo, carecen de cualquier mínimo instrumento de descripción. Esta circunstancia es relativamente frecuente en la mayor parte de los fondos de origen privado, que se recibieron -en la mayoría de los casos- sin la más mínima información o relación de entrega sobre el contenido de los contenedores que los albergaban. Y lo que es más grave aún, no se ha conservado registro original alguno -que debieron de existir, pues muchos de ellos conservan una secuencia numérica de los clichés- de los archivos de negativos de los distintos fotógrafos o estudios comerciales ${ }^{10}$. La única posibilidad, en estas circunstancias, es tomar como referencia inicial la información escrita que aparece en los sobres y cajas originales (tanto textual como numérica), aunque en ocasiones, por desgracia, tampoco se corresponde con su contenido. Con esta información, añadiendo los datos físicos de las imágenes (número de fotografías, formatos, soportes, etc.) y realizando un signaturado provisional sobre los contenedores originales, se procede a realizar un primer inventario topográfico del fondo o colección, que servirá como principal instrumento para avanzar y priorizar su procesado y, en un segundo término, acometer las tareas de identificación, instalación definitiva, descripción y digitalización ${ }^{11}$. 
Para la descripción del material fotográfico se utiliza -como en el resto de fondos del Archivo- la Norma Internacional de Descripción Archivística, ISAD $(G)$, a la que se han añadido algunos sub-campos específicos adicionales en el elemento 1.5. "Volumen y soporte de la unidad de descripción" para recoger otro tipo de información necesaria en este material, como son los de "dimensiones" (en mm), "soporte" (vidrio, plástico, papel), "tipo de imagen” (positivo / negativo) y "tono" (blanco y negro / color).

La $\operatorname{ISAD}(\mathrm{G})$, que ya cuenta a nivel nacional con diversas y buenas adaptaciones para descripción de fotografías, como las de Boadas, Casellas y Suquet (2001) y Cid González et al. (2006); aporta, entre otros beneficios como la estandarización, la aplicación del concepto de descripción multinivel en la representación de los conjuntos fotográficos; contando, en una misma herramienta la información referida al fondo o colección, para ir descendiendo a los niveles inferiores, concretamente los llamados "niveles de descripción físicos", que en el caso de la fotografías serían tanto el de unidad documental compuesta (reportaje, secuencia) como el de unidad documental simple (fotografía concreta). Conviene indicar, asimismo, que en nuestro caso las fotografías están descritas en la misma base de datos y se consultan en el mismo catálogo que el resto de documentos del archivo; lo que permite -entre otras cosas- enlazar descripciones de ambos tipos de documentos cuando es necesario (por ejemplo, una imagen con el expediente de donde procede), así como utilizar las mismas listas de encabezamientos.

Al mismo tiempo, con la información de contexto disponible, se realiza la correspondiente ficha del productor de las imágenes, bien sea una persona física o fotógrafo, bien se trate de una entidad (empresa fotográfica, institución pública...), a partir de la Norma Internacional sobre Encabezamientos Autorizados Archivísticos para Entidades, Personas y Familias, ISAAR (CPF); cuya información siempre está disponible para el usuario desplegando el campo de "Nombre del productor".

En la descripción de las fotografías se incluyen, además, descriptores o puntos de acceso de tipo geográfico, de personas y entidades y de materias. En esta última categoría queda mucho por hacer, pues falta decidir entre la posibilidad de establecer un listado de materias específico sobre fotografías (que incluya tanto aspectos técnicos como información de género/forma y del contenido iconográfico de las imágenes) u optar por la adopción de algún tesauro que recoja, de forma jerarquizada y relacionada, toda esta información. Puede verse la última aportación a este respecto en García Cárceles y Rodríguez Molina (2014). 


\section{4.- Digitalización}

Actualmente la digitalización del patrimonio cultural en su conjunto se considera prioritaria, tanto por criterios de conservación del material original como por las posibilidades de difusión que permiten las copias digitales e, incluso, como generadores de riqueza en el ámbito de las industrias culturales (Comisión Europea, 2014). Todas estas consideraciones resultan especialmente relevantes en el caso de la fotografía, sobre todo cuando nos enfrentamos a colecciones de negativos cuya manipulación y acceso a su contenido por parte del usuario presenta notables dificultades.

Pero, una vez más ¿cómo priorizar qué colecciones fotográficas deben ser digitalizadas en primer lugar? ¿Cómo conjugar los intereses de usuarios e investigadores con la planificación del trabajo del centro? La digitalización ¿debe ser una de las primeras tareas o debe culminar el proceso de tratamiento del material fotográfico? Entre los criterios que determinan la digitalización de un determinado conjunto fotográfico se encuentran los de antigüedad y rareza del material, estado de conservación, frecuencia o potencialidad de utilización por parte de los usuarios, calidad e interés del contenido o autoría de las fotografías.

En el Archivo General la digitalización de una fotografía, de acuerdo con los parámetros técnicos de formatos y resolución establecidos por nuestra unidad de Reprografía ${ }^{12}$, se realiza una vez que, al menos, ésta ha sido limpiada, instalada, signaturada, evaluada y mínimamente inventariada; nunca antes. A efectos de conservación de los originales, se procura que estas tareas previas, así como la digitalización, que implican la manipulación de los originales fotográficos -especialmente por lo que se refiere a los negativos- se realicen de forma consecutiva, para no tener que volver a manejar el material, salvo en circunstancias excepcionales.

Pero la digitalización también puede ser utilizada como un primer instrumento de información o de acceso al contenido de las fotografías. En algunas colecciones compuestas por numerosos rollos o tiras de película de paso universal se ha procedido al contactado digital masivo de los mismos inmediatamente después de su limpieza, signaturado e instalación en hojas transparentes de conservación. Dichas hojas (compuestas por siete fundas y con capacidad, por tanto, para 42 fotogramas), son fotografiadas sobre una mesa de luz con una cámara digital instalada en una columna de reproducción y conectada a un ordenador. A la imagen digital obtenida se le invierte la polaridad, lo que nos proporciona una hoja de miniaturas de fotografías en positivo, similar a los tradicionales contactos obtenidos por revelado químico, de una calidad aceptable que nos permite ampliar la imagen para apreciar el contenido y seleccionar, para posteriores usos o tratamientos, aquellas fotografías o reportajes que se ne- 
cesiten.

El procedimiento, relativamente rápido y mecánico, posibilita obtener un positivado de grandes cantidades de fotografías en poco tiempo y sin necesidad de un manipulado excesivo de los originales.

\section{5.- Consulta y difusión}

El acceso al material fotográfico del Archivo se puede realizar tanto de forma presencial como a distancia, a través de copias digitales. La consulta presencial se realiza en la sala de investigación del centro, en su horario de apertura habitual, bien a través del catálogo informático del Archivo o, para las colecciones históricas del CEHIFORM, a partir de una colección de álbumes de contactos que se encuentran a disposición de los usuarios como un instrumento de descripción más. Además de las Normas para consulta y reproducción de documentos del Archivo General (Región de Murcia. Dirección General de Bienes Culturales, 2012), en el caso del material fotográfico, debido a su especificidad y fragilidad, se ha establecido un protocolo que permite consultar los positivos en sala, bajo la supervisión de un técnico, pero excluye la consulta directa de los negativos y diapositivas. Cuando el material se encuentra digitalizado se suministra la copia digital y, en caso de no haberse reproducido aún, se procede a la digitalización de las fotografías que demanda el usuario.

El principal medio de difusión con que cuenta actualmente el Archivo es su sitio web (archivogeneral.carm.es), puesto en marcha a finales de 2012, y donde se ha querido dar un protagonismo especial a los recursos fotográficos con que contamos. De hecho, desde la misma página principal se accede a dos apartados relacionados con la materia: el "Álbum Familiar de la Región de Murcia” y una "Galería de imágenes”, donde se muestran diversas selecciones de documentos en las que, de nuevo, la fotografía es uno de los principales recursos. También se puede acceder a las colecciones fotográficas a través del cuadro de clasificación del Archivo ${ }^{13}$, pero es el catálogo o buscador la herramienta principal para localizar fotografías o reportajes concretos, con o sin imágenes digitales asociadas. Actualmente la base de datos cuenta con unos 5.300 registros descriptivos referidos a colecciones, álbumes, reportajes o fotografías simples (a los que habría que añadir otros 3.800 referidos a expedientes o documentos que cuentan con fotografías en su interior) y da acceso a unas 9.850 fotografías digitalizadas, sin marca de agua alguna y con una calidad aceptable, asociadas a los mismos. Como se puede comprobar, una ínfima parte si se compara con el volumen total de fotografías que se conservan; pero el continuo incremento de descripciones y copias digitales - labor que realmente comenzó a finales de 2011- permitirá a medio plazo el acceso a un mayor número de contenidos fotográficos. 
Además, en el sitio web del Proyecto Carmesí, mantenido por la Fundación Integra, se encuentran digitalizadas y accesibles, clasificadas por fotógrafos y materias, casi 30.000 fotografías correspondientes a doce de las colecciones históricas procedentes del CEHIFORM (y actualmente conservadas en el Archivo General), que fueron digitalizadas mediante un acuerdo de colaboración en 2008 y subidas al portal "Región de Murcia Digital"14. El Archivo General cuenta con copia digital de alta calidad de las imágenes, a partir de las cuales se sirven las reproducciones solicitadas por los usuarios.

A corto plazo se pretende que una importante selección de documentos del Archivo, en la que tendrá un peso notable la fotografía, se incluya en un repositorio digital que cuente con el modelo de metadatos OAI-PMH (Open Archives Initiative - Protocol for Metadata Harvesting) y que permitirá la diseminación de las descripciones archivísticas, así como sus imágenes digitales asociadas, y su recolección y difusión a través de agregadores como Hispana y Europeana, lo que sin duda incrementará su visibilidad y uso.

Además de estas herramientas de difusión, tanto desde el CEHIFORM como desde el Archivo General, se han venido realizando desde el año 2003 numerosas exposiciones de sus fondos fotográficos (también de la obra de otros fotógrafos murcianos o relacionados con la Región), la mayoría de las cuales han contado con la edición de sus respectivos catálogos. En aras a un mayor conocimiento de estas publicaciones, el Archivo ha digitalizado, en colaboración con Ediciones Tres Fronteras y Google Books, la mayor parte de las mismas, que pueden ser consultadas en su sitio web (menú "eArchivo > Publicaciones en línea”).

\section{6.- Cooperación}

Ya hemos adelantado algunas de las colaboraciones y sinergias que ha establecido el Archivo para coadyuvar a la conservación y conocimiento de sus fondos fotográficos. El centro ha conseguido aunar los esfuerzos de personas y entidades de nuestro ámbito geográfico interesadas en el patrimonio fotográfico. Además de la colaboración con la Fundación Integra en la coordinación del Proyecto Carmesí, existe una estrecha relación con el Departamento de Historia del Arte de la Universidad de Murcia, fundamentalmente a través del profesor de Historia de la Fotografía Fernando Vázquez Casillas, antiguo responsable del CEHIFORM (2008-2010) e impulsor del Laboratorio de Fotografía ${ }^{15}$, con el que se colabora en temas de investigación, formación y difusión de fondos fotográficos.

En este sentido, el Archivo recibe anualmente alumnos en prácticas tanto de la Universidad de Murcia (especialidad de Historia del Arte), como de la Escuela 
de Arte (ciclo superior de Fotografía) y del Instituto de Enseñanza Secundaria Ramón y Cajal (ciclo formativo de grado medio de Laboratorio de Imagen), que nos ayudan en el procesamiento, descripción y digitalización de material fotográfico, con notables beneficios para ambas partes.

Asimismo, contamos con la colaboración desinteresada de especialistas, como el investigador y coleccionista Gerardo Acereda Valdés (autor de diversas publicaciones sobre cámaras fotográficas españolas y de historia de la fotografía), y con organizaciones como la Asociación de Informadores Gráficos de Prensa y Televisión de Murcia, que desde 2007 organizan en el Archivo una exposición anual con una selección de sus mejores trabajos bajo el título "Fotoperiodismo Región de Murcia".

El Archivo facilita copias de fotografías para todo tipo de exposiciones y publicaciones. Sin afán de exhaustividad y a modo de ejemplo, entre las colaboraciones de este tipo en los últimos meses destaca la aportación de varias imágenes al Diccionario de Fotógrafos españoles (Rubio, 2013) o la cesión de otras para exposiciones como España a través de la fotografía (Jiménez Burillo, 2013) y 20 aniversario del Festival "La Mar de Músicas" de Cartagena (julio-agosto de 2014).

Por último, el Archivo General, en representación de la Comunidad Autónoma de la Región de Murcia, forma parte de la comisión que está redactando el Plan Nacional Conservación Patrimonio Fotográfico, coordinado por el Instituto de Patrimonio Cultural de España, que tiene prevista su presentación en 2015.

\section{Epílogo. ¿Por qué y para qué conservar los fondos fotográficos?}

Durante las últimas décadas la fotografía se ha reivindicado como un recurso de información de primer orden y se ha revalorizado como fuente documental para investigaciones de todo tipo (históricas, artísticas, sociales, etnológicas, etc.) así como para el disfrute de la ciudadanía. Sin duda, la "democratización" en la captura y la difusión de las imágenes que ha supuesto la fotografía digital e Internet, especialmente por lo que se refiere a las redes sociales, ha servido para que la población en general se interese por el patrimonio fotográfico; si bien el uso e intercambio indiscriminado de fotografías, sin la más mínima calidad, identificación de autores, fechas y contenidos, así como la falta de respeto a los derechos de propiedad intelectual, tienden a banalizar un tanto este recurso.

Al mismo tiempo, la irrupción de la fotografía digital, que supone un cambio 
de paradigma y plantea sus propios desafíos de gestión (diversidad de formatos, transferencias de las imágenes, problemas de conservación y de migración, posibilidades de uso y difusión), a los que ya se está haciendo frente desde el Archivo, ha hecho tomar conciencia de la necesidad de preservar la fotografía de procesado químico (personalmente no me agrada el neologismo "fotografía analógica”), en centros que cuenten con el personal y los recursos adecuados.

Entre los objetivos que persigue el Archivo General de la Región de Murcia desde que asumió el papel de custodio y divulgador del patrimonio fotográfico en su ámbito territorial, se encuentra -por último, pero no en orden de prelación- el de la sensibilización social respecto al valor de este patrimonio. En definitiva, concienciar a las instituciones públicas, entidades privadas y ciudadanos sobre la importancia de que conozcamos, conservemos y utilicemos este acervo común, así como la necesidad de que se alleguen recursos para su preservación y de que se promueva la investigación y el disfrute colectivo sobre el mismo. En esas líneas de actuación se encuentra el Archivo General, en una labor constante pero, al mismo tiempo, inagotable.

\section{Apéndice. Relación de los principales fondos y colecciones fotográficas del AGRM}

Siguiendo la subdivisión del grupo de fondos "E. Fondos y colecciones fotográficos" se destacan aquí aquellos de más relevancia actualmente:

\section{E.01. / Fotografías de instituciones públicas}

\section{Fondo o colección: Diputación Provincial de Murcia}

Fechas extremas: 1940-1982

Volumen: 1.500 fotografías aproximadamente

Soportes y formatos: Predominan los positivos en papel

Temática principal: Actos institucionales, concursos de embellecimiento de pueblos, obras públicas, actos culturales

\section{Fondo o colección: Comunidad Autónoma de la Región de Murcia}

Fechas extremas: 1982-2000

Volumen: 6.000 fotografías aproximadamente

Soportes y formatos: Predominan los positivos en papel

Temática principal: Actos institucionales, promoción turística, patrimonio histórico-artístico, certámenes juveniles y culturales

Fondo o colección: Consejo Regional de Murcia

Fechas extremas: 1978-1979 
Volumen: 123 fotografías

Soportes y formatos: Positivos en papel

Temática principal: Actos institucionales

Fondo o colección: Casa José Antonio, Hogar Provincial del Niño

Fechas extremas: 1958-1982

Volumen: 537 fotografías

Soportes y formatos: Positivos en papel

Temática principal: Actividades y actos institucionales en el internado, excursiones

Fondo o colección: Casa de la Cultura de Murcia

Fechas extremas: 1955-1986

Volumen: 245 fotografías

Soportes y formatos: 229 positivos en papel y 16 negativos de plástico, $60 \times 60 \mathrm{~mm}$

Temática principal: Actos culturales (exposiciones, conferencias, actuaciones), vistas de las instalaciones

Fondo o colección: Obra Sindical del Hogar

Fechas extremas: 1955-1974

Volumen: 647 fotografías

Soportes y formatos: Positivos en papel

Temática principal: Promociones de viviendas

Fondo o colección: Delegación Provincial de Vivienda y Obras Públicas

Fechas extremas: 1960-1982

Volumen: 800 fotografías aproximadamente

Soportes y formatos: Positivos en papel

Temática principal: Promociones de viviendas

Fondo o colección: Junta Delegada de Incautación y Recuperación del Tesoro Artístico de Murcia / Servicio de Recuperación del Tesoro Artístico Nacional de Murcia

Fechas extremas: c.1937-c.1960

Volumen: 1.971 fotografías

Soportes y formatos: Negativos sobre placa de vidrio y plástico, positivos en papel

Temática principal: Patrimonio histórico-artístico y etnográfico regional 
Fondo o colección: Colección de obras de arte del Museo de Bellas Artes de Murcia

Fechas extremas: c.1920-1996

Volumen: 2.227 fotografías

Soportes y formatos: 1.856 negativos de vidrio y plástico, 359 positivos en papel y 12 diapositivas.

Temática principal: Registro fotográfico de la colección de obras de arte del Museo

\section{E.02. / Fotografía comercial (estudios y fotógrafos) ${ }^{16}$}

Fondo o colección: Colección de 'vintages' o copias en papel de diversos fotógrafos de la Región de Murcia

Fechas extremas: c.1865-c.1975

Volumen: 792 fotografías

Soportes y formatos: Positivos en papel

Temática principal: Retratos de estudio

Fondo o colección: Fotografía Casaú (Cartagena)*

Fechas extremas: 1915-1980

Volumen: 11.008 fotografías

Soportes y formatos: Negativos de vidrio y plástico (10.008), positivos en papel (749) y copias digitales (251)

Temática principal: Retratos de estudio, reportaje social

Fondo o colección: Fernando Navarro, fotógrafo (Totana)*

Fechas extremas: 1885-1916

Volumen: 2.825 fotografías

Soportes y formatos: Negativos de vidrio (2.819) y positivos en papel (6) Temática principal: Retratos de estudio

Fondo o colección: Fotografía Martínez Blaya (Cartagena)*

Fechas extremas: 1932-2004

Volumen: 52.000 fotografías aproximadamente

Soportes y formatos: Negativos de vidrio y plástico, diapositivas

Temática principal: Retratos de estudio, reportaje social, fotografía industrial y comercial, espectáculos

Fondo o colección: Antonio Abellán, fotógrafo (Cartagena)*

Fechas extremas: 1947-1975 
Volumen: 6.107 fotografías

Soportes y formatos: Predominan los negativos de plástico, algunos positivos en papel

Temática principal: Retratos de estudio, reportaje social, compañías de seguros

Fondo o colección: Fotos López (Cehegín)*

Fechas extremas: 1955-2003

Volumen: 200.000 fotografías aproximadamente

Soportes y formatos: Negativos de plástico de distintos formatos

Temática principal: Retratos de estudio, reportaje social, fiestas y actos locales

Fondo o colección: Luis Canicio, fotógrafo (Jumilla)

Fechas extremas: 1955-2003

Volumen: 77.000 fotografías aproximadamente

Soportes y formatos: Predominan los negativos de plástico y, en menor medida, positivos en papel y diapositivas

Temática principal: Retratos de estudio, reportaje social, fiestas y actos locales

\section{E.03. / Fotoperiodismo}

Fondo o colección: Diario 16 de Murcia

Fechas extremas: 1991-1999

Volumen: 40.000 fotografías aproximadamente

Soportes y formatos: Predominan los positivos en papel. En menor medida, negativos de $35 \mathrm{~mm}$ y diapositivas

Temática principal: Fotoperiodismo

Fondo o colección: Carlos Gallego, fotoperiodista

Fechas extremas: 1983-2002

Volumen: 440.000 fotografías aproximadamente

Soportes y formatos: Predominan negativos de plástico de $35 \mathrm{~mm}$ y formatos digitales. En menor medida, diapositivas y positivos en papel Temática principal: Fotoperiodismo, reportajes internacionales

Fondo o colección: Ángel Martínez Requiel, fotoperiodista y fotógrafo comercial 
Fechas extremas: 1974-2002

Volumen: 160.000 fotografías aproximadamente

Soportes y formatos: Predominan negativos de plástico $35 \mathrm{~mm}$ y diapositivas de varios formatos

Temática principal: Fotoperiodismo, fotografía institucional y comercial

\section{E.04. / Colecciones fotográficas privadas y de fotógrafos amateurs}

Fondo o colección: Joaquín Padilla*

Fechas extremas: 1984-1981

Volumen: 2.133 fotografías

Soportes y formatos: Negativos de plástico

Temática principal: Fotografía de autor, paisaje, reproducciones de fotografías antiguas de Murcia

Fondo o colección: Manuel Rodríguez de Viguri, fotógrafo amateur* Fechas extremas: c.1930-c.1960

Volumen: 625 fotografías

Soportes y formatos: Negativos de vidrio y de plástico de distintos formatos

Temática principal: Familiar, fotografía militar (baterías de costa y campaña de la División Azul en Rusia)

Fondo o colección: Juan Orenes Gambín*

Fechas extremas: 1960-1980

Volumen: 638 fotografías

Soportes y formatos: Negativos de plástico

Temática principal: Fotografía de autor, paisajes, Semana Santa

Fondo o colección: Álbum Familiar de la Región de Murcia

Fechas extremas: 1857-1999

Volumen: 2.300 fotografías aproximadamente

Soportes y formatos: Copias digitales

Temática principal: Reproducciones de fotografías de más de cien colecciones particulares

Fondo o colección: Colección fotográfica del poeta Vicente Medina Fechas extremas: c.1880-c.1937 
Volumen: 359 fotografías

Soportes y formatos: Copias digitales de negativos y positivos de la Fundación V. Medina

Temática principal: Fotografía costumbrista, familiares

Fondo o colección: Luciano de la Calzada Rodríguez, catedrático de Universidad y político

Fechas extremas: 1932-1986

Volumen: 2.531 fotografías

Soportes y formatos: Positivos en papel

Temática principal: Familiares, viajes, actividad política (presidente de la Confederación Hidrográfica del Segura) y universitaria (Decano de la Facultad de Letras)

Fondo o colección: Familia Ruano Mazzuchelli (Cieza)

Fechas extremas: c.1890-c.1940

Volumen: 278 fotografías

Soportes y formatos: Negativos de vidrio (162), diapositivas sobre vidrio (3) y positivos en papel (113)

Temática principal: Familiar, vistas y paisajes

Fondo o colección: Juan Antonio Molina Serrano, arquitecto

Fechas extremas: 1978-2000

Volumen: 956 fotografías

Soportes y formatos: Positivos en papel

Temática principal: Proyectos de arquitectura y restauración monumental, urbanismo

Fondo o colección: Colección de fotografías y postales de la familia Martínez Plazas

Fechas extremas: c. 1890-c.2000

Volumen: 1.856 fotografías y tarjetas postales

Soportes y formatos: 1.227 positivos en papel, 79 negativos de plástico, 2 diapositivas y 548 tarjetas postales

Temática principal: Retratos y reportajes familiares, boy scouts, Obra Sindical de Educación y Descanso, Coros y Danzas, tarjetas postales nacionales e internacionales

Fondo o colección: Gustavo Gillman Bover, ingeniero y fotógrafo Fechas extremas: 1891-1921 
Volumen: 446 fotografías

Soportes y formatos: Predominan negativos de plástico y, en menor medida, de vidrio

Temática principal: Ferrocarril, minería, costumbrista y etnológica, viajes

Fondo o colección: Daniel Jiménez de Cisneros y Hervás, paleontólogo

Fechas extremas: 1903-c.1930

Volumen: 231 fotografías

Soportes y formatos: Predominan los negativos de vidrio

Temática principal: Excursiones científicas, fósiles, vistas de ciudades y paisajes e imágenes familiares

Fondo o colección: Mariano Ruiz-Funes García, jurista y político

Fechas extremas: 1909-c.1954

Volumen: 207 fotografías

Soportes y formatos: Positivos en papel y copias digitales

Temática principal: Familiares, actividad docente y política y exilio en América

Fondo o colección: Antonio Pérez Crespo, político y escritor

Fechas extremas: 1968-2011

Volumen: 895 fotografías

Soportes y formatos: Positivos en papel

Temática principal: Actividad oficial (presidente de la Junta del Puerto de Cartagena, presidente del Consejo Regional de Murcia y de UCD en Murcia, diputado y senador), actos culturales

Fondo o colección: Orfeón Murciano Fernández Caballero

Fechas extremas: 1933-1987

Volumen: 552 fotografías

Soportes y formatos: Positivos en papel

Temática principal: Actuaciones musicales y viajes, fotografías de socios

Fondo o colección: Emeterio Cuadrado, arqueólogo e ingeniero

Fechas extremas: 1944-1996

Volumen: 6.939 fotografías

Soportes y formatos: 3.525 negativos de plástico y 156 de vidrio, 3.260 positivos en papel

Temática principal: Yacimientos arqueológicos, colecciones museísticas, 
viajes culturales, obras públicas

Fondo o colección: Pedro San Martín Moro, arquitecto

Fechas extremas: 1948-2000

Volumen: 40.000 fotografías aproximadamente

Soportes y formatos: Negativos de plástico, diapositivas y positivos en papel

Temática principal: Arqueología, restauración de monumentos, viajes

\section{E.05. / Colecciones temáticas de fotografía}

Fondo o colección: Colección de postales y otro material gráfico referido a la Región de Murcia

Fechas extremas: 1843-1996

Volumen: 1.489 tarjetas postales ilustradas y 121 fotografías

Soportes y formatos: Fototipia y positivos en papel

Temática principal: Vistas de localidades, monumentos y paisajes, reproducciones de fotografías antiguas de Murcia

Fondo o colección: Colección fotográfica de "La Orden de la Santísima Trinidad en Murcia”, de José Crespo

Fechas extremas: c. 1970

Volumen: 596 fotografías

Soportes y formatos: Negativos de plástico

Temática principal: Patrimonio histórico, urbanismo de Murcia, reproducciones de documentos

Fondo o colección: Colección de vistas estereoscópicas a la albúmina Fechas extremas: $1858-1880$

Volumen: 60 fotografías

Soportes y formatos: Pares de positivos en papel de 70 x $70 \mathrm{~mm}$, montadas sobre cartulinas o cartones de $85 \times 175 \mathrm{~mm}$

Temática principal: catedrales de Huesca y Zaragoza, monumentos y localizaciones de Roma, Génova y París, y escenas de interior

Fondo o colección: Colección de fotografías de fútbol

Fechas extremas: 1941-1963

Volumen: 332 fotografías

Soportes y formatos: Positivos en papel

Temática principal: Encuentros de fútbol del Valencia CF y de la UD 
Levante o celebrados en sus estadios

Fondo o colección: Fotografías aéreas del "Vuelo Ruiz de Alda" sobre la cuenca del río Segura

Fechas extremas: 1928-1932

Volumen: 6.193 fotografías

Soportes y formatos: Copias digitales

Temática principal: Fotogrametría aérea

Fondo o colección: Fotografías aéreas del "Vuelo americano" sobre la provincia de Murcia

Fechas extremas: 1956

Volumen: 1.061 fotografías

Soportes y formatos: Copias digitales

Temática principal: Fotogrametría aérea

Fondo o colección: Colección de negativos para postales de la Región de Murcia de Fototipia Thomas

Fechas extremas: c.1910-c.1930

Volumen: 120 fotografías

Soportes y formatos: Negativos de plástico de 100 x $150 \mathrm{~mm}$

Temática principal: Vistas de Archena, Cartagena y Murcia

Fondo o colección: Colección de negativos para postales de la Región de Murcia de Ediciones Arribas

Fechas extremas: c.1950-c.1970

Volumen: 475 fotografías

Soportes y formatos: Negativos de vidrio y plástico de 100 x $150 \mathrm{~mm}$ Temática principal: Vistas de localidades, monumentos y obras de arte

Fondo o colección: Fotografías aéreas y terrestres de la Región de Murcia de la empresa FOAT

Fechas extremas: 1965-1995

Volumen: 345 fotografías

Soportes y formatos: Negativos de plástico en color y en blanco y negro de diferentes formatos

Temática principal: En su mayor parte, fotografía aérea oblicua de localidades y monumentos de la Región 


\section{4.- Bibliografía:}

BOADAS, J., CASELLAS, Ll.-E. y SUQUET, M. À., 2001. Manual para la gestión de fondos y colecciones fotográficas. Girona: CCG Ediciones. ISBN 978-84-95483-11-9 Reproducción digital disponible en: http://www.girona.cat/sgdap/docs/o256_Manual_Fotografic.pdf [Consulta: 13 noviembre 2014]

CASELLAS SERRA, Ll-E., 2007. La gestión archivística de los fondos y colecciones fotográficas. En El documento escrito y el documento fotográfico. Las Palmas de Gran Canaria: Anroart, pp. 54-79. ISBN 978-84-96577-89-3

CID GONZÁLEZ, T. et al., 2006. MDM Convenciones: fondos fotográficos, Valladolid: Junta de Castilla y León. Disponible en: http://www.aefp.org.es/NS/Documentos/NormasDescriptivas/ MDM2Convenciones_FondFotograf.pdf [Consulta: 19 noviembre 2014]

COMISIÓN EUROPEA, 2014. Cultural heritage: Digitisation, online accessibility and digital preservation. Report on the Implementation of Commission Recommendation 2011/711/EU. Bruselas: Comisión Europea. Disponible en: http://ec.europa.eu/digital-agenda/en/news/european-commissionsreport-digitisation-online-accessibility-and-digital-preservation-cultural [Consulta: 19 noviembre 2014]

DÍAZ BURGOS, J. M. et al., 2003. Fotografía en la Región de Murcia. Murcia: Murcia Cultural.

GARCÍA CÁRCELES, M. y RODRÍGUEZ MOLINA, Ma J., 2014. Elaboración de tesauros para fotografía basados en géneros fotográficos. Boletín ANABAD, LXIV(1), pp. 87-100. ISSN 02 10-4164

JIMÉNEZ BURILLO, P. (dir.), 2013. España a través de la fotografía, 1839-2010. Taurus: Fundación MAPFRE.

LAVÉDRINE, B., 2010. (re)Conocer y conservar las fotografías antiguas. París: Editions du Comite des Travaux historiques et scientifiques. ISBN 978-2-7355-0710-8

MESTRE I VERGÉS, J., 2003. Identificación y conservación de fotografías. Gijón: Trea. ISBN 849704-089-9

PAVÃO, L., 2001. Conservación de colecciones de fotografía. Sevilla: Junta de Andalucía, Consejería de Cultura. ISBN 84-8266-174-4

REGIÓN DE MURCIA, 2001. Orden de 16 de noviembre de 2001 de la Consejería de Turismo y Cultura por la que se crea el Centro Histórico-Fotográfico de la Región de Murcia. Boletín Oficial de la Región de Murcia, No 275, 27 de noviembre de 2001, p. 15.207.

REGIÓN DE MURCIA. Dirección General de Bienes Culturales, 2012. Resolución de la Dirección General de Bienes Culturales por la que se establecen las Normas para consulta y reproducción de documentos del Archivo General de la Región de Murcia. Disponible en: http://estaticoarchivo.carm.es/ adjuntos/DOC24560693939_485_NORMASCONSULTAYREPRODUCCION.pdf [Consulta: 19 noviembre 2014]

RUBIO, O. M. (dir.), 2013. Diccionario de Fotógrafos españoles: del siglo XIX al XXI. Madrid: La Fábrica: Acción Cultural Española. ISBN 978-84-15691-09-9 


\section{5.- Notas}

1 Hasta 2007 se publicaron siete monografías, dedicadas a Fernando Navarro (2002), José Rodrigo (2002), Los Tani (2003), Carlos Gallego (2003), Saturnino Espín (2005) y Pedro Menchón (2007).

2 Disponible en: http://archivoweb.carm.es/archivoGeneral/arg.contenido? seccion=CuadroClasificacion\&idsec $=321 \&$ pa_el_div $=. /$ arg.estructura.crea_div_cuadroclasificacion? pidses $=0 \#$ (Consulta: 13 noviembre 2014).

3 Se trata de una vista estereoscópica a la albúmina, con la siguiente anotación manuscrita de la época en el reverso: "Zaragoza 1858. Capilla del Cristo del Aseo (sic, por La Seo)", que forma parte de un grupo de imágenes similares datadas entre esa fecha y 1860. AGRM, FOT_POS,30/004.

4. Conviene aclarar, para los no especialistas en archivística, que el nombre del productor no necesariamente coincide con el del autor de la fotografía. Un ejemplo ilustrará mejor esto: una fotografía en papel de un edificio en construcción en la Cartagena de los años sesenta, realizado por Fotografía Casaú, pertenece y se adscribe al fondo de la Obra Sindical del Hogar (productor), no al fondo de esa empresa fotográfica, que también se conserva en nuestro archivo. En todo caso, la autoría de Casaú quedará reflejada en el registro descriptivo de la fotografía bien como productor secundario, bien en el campo "alcance y contenido" o como una referencia de descriptor de entidades.

5 Por ejemplificarlo de una forma gráfica: no es tan prioritario ni es posible aplicar el mismo número de recursos a la intervención sobre el fondo de un estudio fotográfico comercial, con decenas de miles de retratos de estudio de formato medio de las décadas de los cincuenta a los setenta, que sobre el de una institución que cuenta con una colección de placas fotográficas de vidrio de gran formato de obras de arte y de monumentos de la década de 1920.

6 Se trató de una iniciativa similar a las llevadas a cabo en otras comunidades autónomas, como "Los legados de la tierra” (Castilla-La Mancha) o el "Archivo Fotográfico de la Comunidad de Madrid”.

7 Se ha tenido la prevención de instalar los negativos, que en muchos casos son de vidrio, en una batería de armarios fijos, para evitar que el movimiento de los armarios compactos pudiera provocar la caída y rotura de algún contenedor de fotografías.

8 Aunque somos conscientes de que los ejemplares de fototitipia no constituyen, estrictamente, fotografías, por motivos de gestión, instalación y conservación se incluyen dentro de esta sigla las colecciones de tarjetas postales.

9 Además de esta sigla genérica, existen otras anteriores -y que se han mantenido- referidas a copias digitales de fotografías asociadas a distintos fondos que se conservan en el Archivo: IAX-DIG (copias de imágenes referidas al Instituto de Enseñanza Secundaria "Alfonso X el Sabio"), FR,MRF (copias de fotografías de Mariano Ruiz-Funes) o JLS_FOT (copias de fotografías de Juan López Sánchez).

10 Existen algunas excepciones a este panorama. La más notable es el caso del ingeniero británico Gustav Gillman, del que se conservan impagables cuadernos donde anotaba una riquísima información de las tomas: fecha de la captura, lugar, tiempo (nublado, soleado), apertura de diafragma, tiempo de exposición, modelo de cámara y título de la fotografía.

11 En el caso de uno de los últimos archivos donados, el del fotoperiodista Ángel Martínez Requiel, la mayor parte del material (rollos de negativo de $35 \mathrm{~mm}$ ) venía envuelto en camisas de papel donde se refería, grosso modo, fecha y acontecimiento, información a partir de la cual se elaboró una base de datos de más de casi 7.500 registros que ha permitido localizar la información gráfica de interés y, 
entre otras utilidades, seleccionar el material para una exposición de fotografías, celebrada recientemente en el Archivo General, así como la edición del libro La mirada de un tiempo: Ángel Martínez Requiel, fotógrafo, Murcia: Ediciones Tres Fronteras, 2014.

12 Las capturas, en escáneres profesionales, se realizan normalmente en formato TIFF con un mínimo de 300 puntos por pulgada para positivos; y para los negativos, en función del tamaño del original, entre 600 y 4.800 p.p.p. A partir de esta imagen primigenia se generan dos copias en formato JPEG: una para consulta y otra más comprimida para la web.

13 Se encuentra en el menú "Información General > Fondos documentales > Cuadro de clasificación", grupo de fondos "E. Fondos y colecciones fotográficas".

14 Fundación Integra ha implementado, además, un blog llamado "Proyecto Carmesí: fotografías para la historia", donde se recogen aportaciones de particulares que colaboran identificando escenas, personas o lugares de las colecciones fotográficas digitalizadas en el proyecto. Disponible en: http:// fotosparalahistoria.blogspot.com.es/ (Consulta: 19 noviembre 2014).

15 http://www.um.es/fotohistoria/?page_id=1071. (Consulta: 21 noviembre 2014).

16 Las fotografías de los fondos marcados con un asterisco están digitalizadas y accesibles, en todo o en parte, en el portal del Proyecto Carmesí: http://www.regmurcia.com/servlet/s.Sl? METHOD=FRMCOLECCIONESFOTOS\&sit=c,373,m,139,serv,Carmesi (Consulta: 14 noviembre 2014). 